\title{
The effects of graduate competency-based education and mastery learning on patient care and return on investment: a narrative review of basic anesthetic procedures
}

\author{
Claus Hedebo Bisgaard ${ }^{1 *}$ (D) Sune Leisgaard Mørck Rubak ${ }^{2}$, Svein Aage Rodt ${ }^{3}$, Jens Aage Kølsen Petersen ${ }^{4}$
} and Peter Musaeus ${ }^{1}$

\begin{abstract}
Background: Despite the widespread implementation of competency-based education, evidence of ensuing enhanced patient care and cost-benefit remains scarce. This narrative review uses the Kirkpatrick/Phillips model to investigate the patient-related and organizational effects of graduate competency-based medical education for five basic anesthetic procedures.

Methods: The MEDLINE, ERIC, CINAHL, and Embase databases were searched for papers reporting results in Kirkpatrick/Phillips levels 3-5 from graduate competency-based education for five basic anesthetic procedures. A gray literature search was conducted by reference search in Google Scholar.

Results: In all, 38 studies were included, predominantly concerning central venous catheterization. Three studies reported significant cost-effectiveness by reducing infection rates for central venous catheterization. Furthermore, the procedural competency, retention of skills and patient care as evaluated by fewer complications improved in 20 of the reported studies.
\end{abstract}

Conclusion: Evidence suggests that competency-based education with procedural central venous catheterization courses have positive effects on patient care and are both cost-effective. However, more rigorously controlled and reproducible studies are needed. Specifically, future studies could focus on organizational effects and the possibility of transferability to other medical specialties and the broader healthcare system.

Keywords: Anesthesia, Graduate medical education, Internship and residency, Catheterization, Central venous, Anesthesia, General, Anesthesia spinal, Anesthesia, Epidural, Airway management, Competency-based education, Mastery learning

\section{Background}

During the past two decades, medical educators and regulators have introduced competency-based education (CBE) and mastery learning (ML) into the graduate medical curriculum in many specialties including anesthesiology $[1,2]$. This narrative review evaluates the patient-related and cost-benefit outcomes in CBE-literature for five basic anesthetic procedures.

\footnotetext{
*Correspondence: claus@cesu.au.dk

${ }^{1}$ Centre for Health Sciences Education, Faculty of Health, Aarhus University, Palle Juul Jensens Boulevard 82, Building B, DK-8200 Aarhus N, Denmark Full list of author information is available at the end of the article
}

\section{Competency-based education}

The origins of CBE can be traced to outcomes-based education in the 1950's, based on behavioristic learning theory [3]. In this theory, the trainees are seen as impressionable to outside influences that create learning outcomes regardless of innate capabilities or processes. Outcomes here are conceived as observable behavioral changes in the trainees following training. This outcome, defined by experts in the field of CBE, is called competence [3]. The duration of training before reaching competence is individual and is a result of both the learner's aptitude and the teaching offered [4]. The variable educational time necessary to reach the fixed outcome of

(c) The Author(s). 2018 Open Access This article is distributed under the terms of the Creative Commons Attribution 4.0 International License (http://creativecommons.org/licenses/by/4.0/), which permits unrestricted use, distribution, and reproduction in any medium, provided you give appropriate credit to the original author(s) and the source, provide a link to the Creative Commons license, and indicate if changes were made. The Creative Commons Public Domain Dedication waiver (http://creativecommons.org/publicdomain/zero/1.0/) applies to the data made available in this article, unless otherwise stated. 
competence is in contrast to the traditional fixed duration of curriculum concluding with a variable outcome assessed by grades [5]. CBE-based courses thus focus on the eventual outcome of the education rather than on the educational methods and duration [6].

Mastery learning can be conceived as a more rigid form of CBE. In ML, a high level of mastery, originally defined as $90 \%$ correct answers, is needed for the learner to progress to a more advanced level of training or to be asserted as proficient [7]. Educationalists such as Keller, Carroll and Bloom proposed that up to $90 \%$ of all learners could reach mastery level if offered the appropriate educational method and the right time for learning the subject $[4,8,9]$. Continuous formative evaluation of learning is necessary for the trainee to reach mastery, identifying parts still needed for remedial teaching before the desired level of mastery is achieved. [10].

\section{CBE in medical education}

Introduced into medical education by McGaghie and colleagues with their World Health Organization paper in 1978 [11], CBE has, particularly since the late 1990's, seen a rapid international growth, dissemination, and adaptation [12]. Large educational governing bodies such as the Accreditation Council for Graduate Medical Education of the USA [13] and Royal College of Physicians and Surgeons of Canada [14] have created overarching competence frameworks to assist in the design and implementation of CBE. These and related frameworks have been implemented in several specialties, among these anesthesiology specialty training programs in the USA, in the UK and in Continental Europe including Denmark [15-24].

One of the driving forces behind the shift to $\mathrm{CBE}$ was the reduced work hours for trainee doctors introduced by governing bodies internationally $[25,26]$. The reduced work hours were thought to decrease the exposure to cases upon which graduate medical education traditionally relied in a fixed-duration training program $[1,27,28]$. CBE and ML are seen as means of enabling a more systematic acquisition of skills, which mitigates the effect of reducing work hours [29]. Specialist accreditation was traditionally awarded by completing the fixed-duration training and by written knowledge tests [30]. CBE and ML are thought to provide more transparent and relevant clinical outcome measures for assessment of specialist accreditation [31].

\section{Criticism of CBE}

Although CBE seems to answer the aforementioned problematic work hour restraint in graduate medical education, it has seen opposition as well. As a result of the enthusiasm it is experiencing, $\mathrm{CBE}$ in graduate medical education is criticized for infallibility, deeming conceptual criticism as invalid [32]. CBE is further thought to atomize the complex field of medical expertise into checklists, concerning itself with subsets of skills or discrete tasks, all the while only evaluating to minimum standards [33-35]. According to critics, the complex order of proficiency or expertise is not directly observable, and $\mathrm{CBE}$ thus risks ignoring the time and experience needed to form proficiency and medical expertise [35-38]. Critique of CBE and ML is further concerned with the potentially increased costs due to enhanced supervision, education of supervisors and the variable duration of training [36, 37, 39].

Considering the time and funding already invested in clinical training [40-45], it is thus relevant to examine whether skills training by $\mathrm{CBE}$ and ML transfers into clinical performance and patient care and delivers a return on investment. Indeed, recent reviews emphasize the need for further research to qualify the effects and identify tangible therapeutic and organizational outcomes [46-52]. An appropriate model of evaluation is necessary to answer this question.

\section{The Kirkpatrick/Phillips model for training evaluation}

The original Kirkpatrick model has four sequential levels: reaction, learning, behavior, and results [53]. Positive results at a lower level are necessary for causal inference of a superior level effect as the result of an education intervention [54]. Phillips added a fifth level, "return on investment", to the four original levels [55]. This fifth level evaluates the trade-off between the costs of the training program and the revenues created by the effects of the program. The costs of the program can be the investment in and maintenance of equipment and salary for the trainers and trainees. Revenues could be decreased complications, shorter hospital stays and added contributions to department clinical services [55].

An adaptation of the Kirkpatrick model to medical education has been proposed by Bewley [56]. This model, with the addition of retention as a measure of sustainable behavioral change over time, is used as inspiration for this review. The resulting adaptation to the Kirkpatrick/Phillips model for training evaluation is presented in Fig. 1.

The appeal of the Kirkpatrick model is the simplicity it proposes to an otherwise complex framework of influences by categorizing the outcome in four categories. The model emphasizes level 4, results, as the most important outcome level that an organization can readily assess if the training adds value. In the case of graduate medical education, level 4 would concern patient care [57]. Furthermore, the Kirkpatrick/Phillips model is also widely used in medical education and is thus readily recognizable to readers $[49,57]$.

The weakness of the Kirkpatrick model is closely related to its strength. The focus on outcomes risks omitting the focus on the process of learning. In addition, the automatic causality inference often implied in Kirkpatrick analyses is seen as overly simplistic [54]. Many 


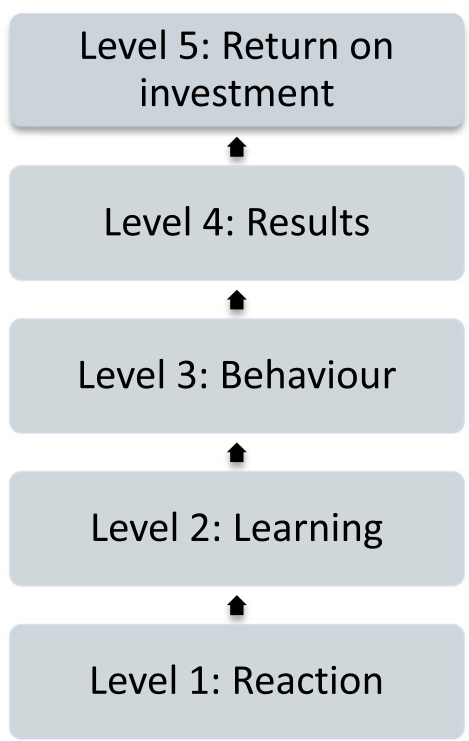

Fig. 1 Kirkpatrick/Phillips, adapted to medical education

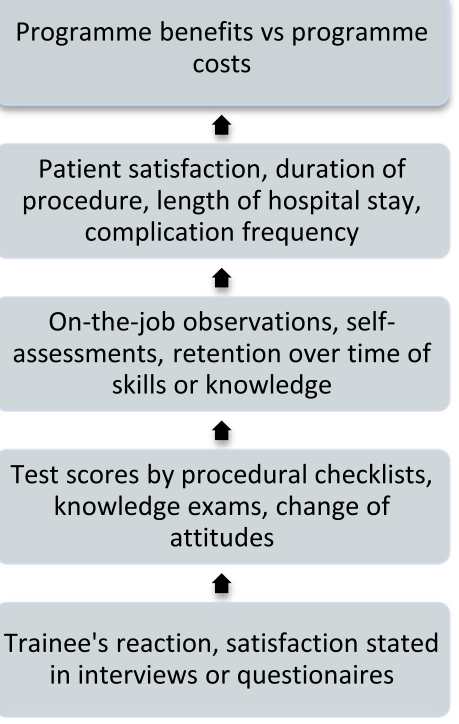

influences other than the training intervention itself can contribute to enhanced results, as exemplified by the Hawthorne effect [58]. Here, the mere extra focus on the subjects of the investigation, rather than the intended intervention, is thought to have produced results.

The Kirkpatrick/Phillips model was chosen for this review as a recognizable framework of clearly defined levels. Using the Kirkpatrick framework as intended, our outcomes should be defined. The outcome of medical education should be the competent physician best suited for the patients' and society's needs [11]. This translates into the competent performance of skills in the treatment of patients, which ultimately leads to enhanced patient care. Training should additionally be cost-effective in order to justify the training expenditures [59]. These criteria translate into effects evaluated by Kirkpatrick/ Phillips levels 3-5.

\section{Study aim}

1. The current narrative review assesses the literature on outcomes pertaining Kirkpatrick/Phillips Levels 3-5 (clinical skills performance, patient care and return on investment) originating from $\mathrm{CBE}$ or $\mathrm{ML}$ training for five basic anesthetic competences: airway management, spinal anesthesia, epidural anesthesia, and central venous catheterization.

2. Furthermore, this review will identify gaps in the literature and discuss the implications for training that could be drawn from this discussion.

3. Finally, future directions for enhancing the evidence will be evaluated.

\section{Methods}

A narrative review, able to encompass a large heterogeneity of studies, was chosen as the best method for the present study for several reasons [60-62]. First, the field of CBE and $\mathrm{ML}$ is broad, covering research from both traditional simulation and workplace learning. A narrative review would enable the evaluations of the evidence, gaps and future directions. Second, the empirical studies encompass different study designs and varied quality in terms of design and measurement. In light of these two characteristics of the literature, we decided to perform a narrative overview of the subject instead of attempting to calculate aggregated effects in a systematic review.

The narrative review was conducted by first defining the searchable keywords by the PICO framework (population, intervention, control, outcome) [63]. The PICO framework is a mnemonic used to break a research question or aim into searchable keywords by categorizing them into four items [64]:

Population: Residents or interns involved in graduate procedural training.

Intervention: Mastery learning or competency-based training courses of the procedures of general anesthesia, airway management, spinal anesthesia, epidural anesthesia/analgesia, and central venous catheterization.

Control: Other intervention, normal or traditional training or none.

Outcome: Reporting a level 3 or superior outcome, including retention over time, according to the Bewley adaptation of the Kirkpatrick/Phillips model for training evaluation. 


\section{Data sources}

A search was conducted using the MEDLINE, ERIC, CINAHL and Embase databases. The search was for English language literature on medical education and anesthesiology literature from January 1946 to August 2017.

Google Scholar was searched for gray literature by reviewing both references included in and papers citing the selected studies from the primary search [65].

\section{Search strategy}

For the primary MEDLINE search, the MeSH terms and Boolean operators "education, medical, graduate" OR "internship and residency" were applied. The search results were subsequently narrowed by combining these terms with the MeSH terms concerning the relevant procedural keywords: "catheterization, central venous" OR "anesthesia, epidural" OR "analgesia, epidural" OR "anesthesia, general" OR "airway management" OR "anesthesia, spinal".

A similar search strategy was conducted in EMBASE.

CINAHL was broadly searched for the words "competency-based education" or "mastery learning" coupled with the procedural keywords. ERIC was searched broadly for the procedural keywords only.

\section{Selection of papers}

The MEDLINE, ERIC, CINAHL and Embase databases were searched. The first author read the titles and abstracts for adherence to the inclusion criteria:

\section{English language}

CBE and ML-training interventions, either declared or undeclared, but in design

Studies concerning postgraduate medical training on resident or intern level

Studies reporting results concerning Kirkpatrick-Phillips levels 3-5, including retention of skills over time.

Published from January 1946 to August 2017. The following exclusion criteria were applied:

Non-CBE and non-ML interventions

Studies only reporting immediate skills acquisition in a simulated setting

Studies reporting the training of medical students, nurses, attending, fellows or specialists.

The author group subsequently read the resulting selection of studies in depth for adherence to the inclusion criteria. From this primary selection, Google Scholar was used to search for references in the papers and papers referring to the primary selected papers [65].

The search strategy and the resulting number of papers are shown in Fig. 2: Selection flowchart.

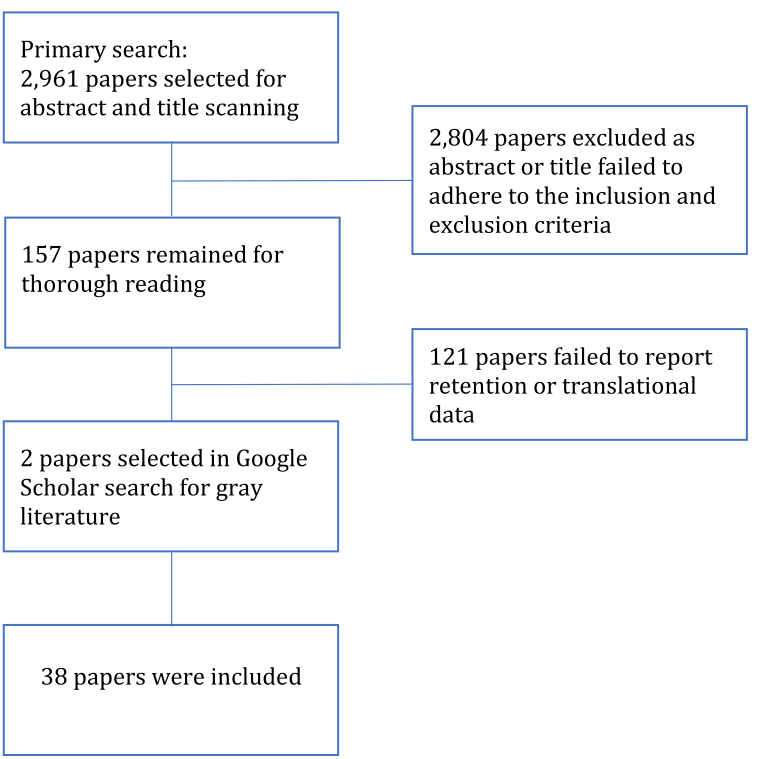

Fig. 2 Selection Process

The author group read the final selection of papers in depth. Data on competency type, intervention training type, duration and number of intervention group trainees were extracted from the papers. Furthermore, data on control group type and training were recorded. Finally, the study outcomes were registered and categorized according to the Kirkpatrick/Phillips model.

\section{Results}

The 38 papers selected for review are shown in Table 1: Selected Studies.

Three papers reported results on Phillips Level 5, return on investment [66-68], all concerned with central venous catheterization. All three demonstrated a return on investment from a novel CBE-training program for CVC-insertion because of a decrease in complications and the related costs.

Eighteen studies showed effects of level 4: learning. They investigated competence in CVC (16 papers), spinal block (1), and airway management (1). For the CVC studies, 9 papers reported rates of complications [66, 68-75], and 3 papers reported needle passes and success rates as predictors of complications [76-78].

A total of 31 papers reported results concerning Kirkpatrick level 3: behavior. CVC was the predominant procedure (22 papers), followed by general anesthesia and airway management (4), epidural (3), and spinal anesthesia (2). Retention of skills was reported in 16 studies [68, 76, 79-92].

\section{Discussion}

Primary findings

The results of all three studies investigating Kirkpatrick Level 5 show cost-saving potential because of prevention 


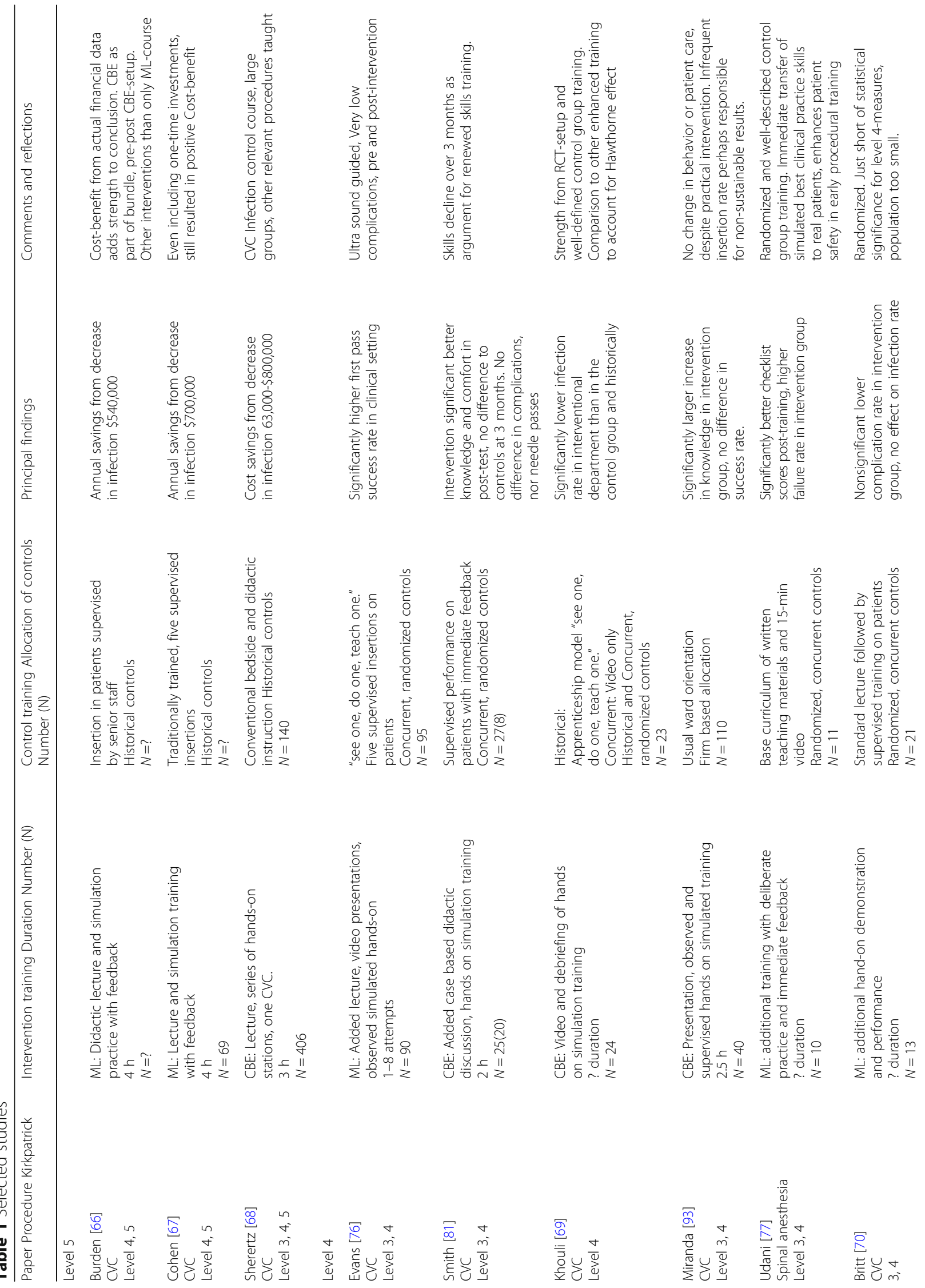




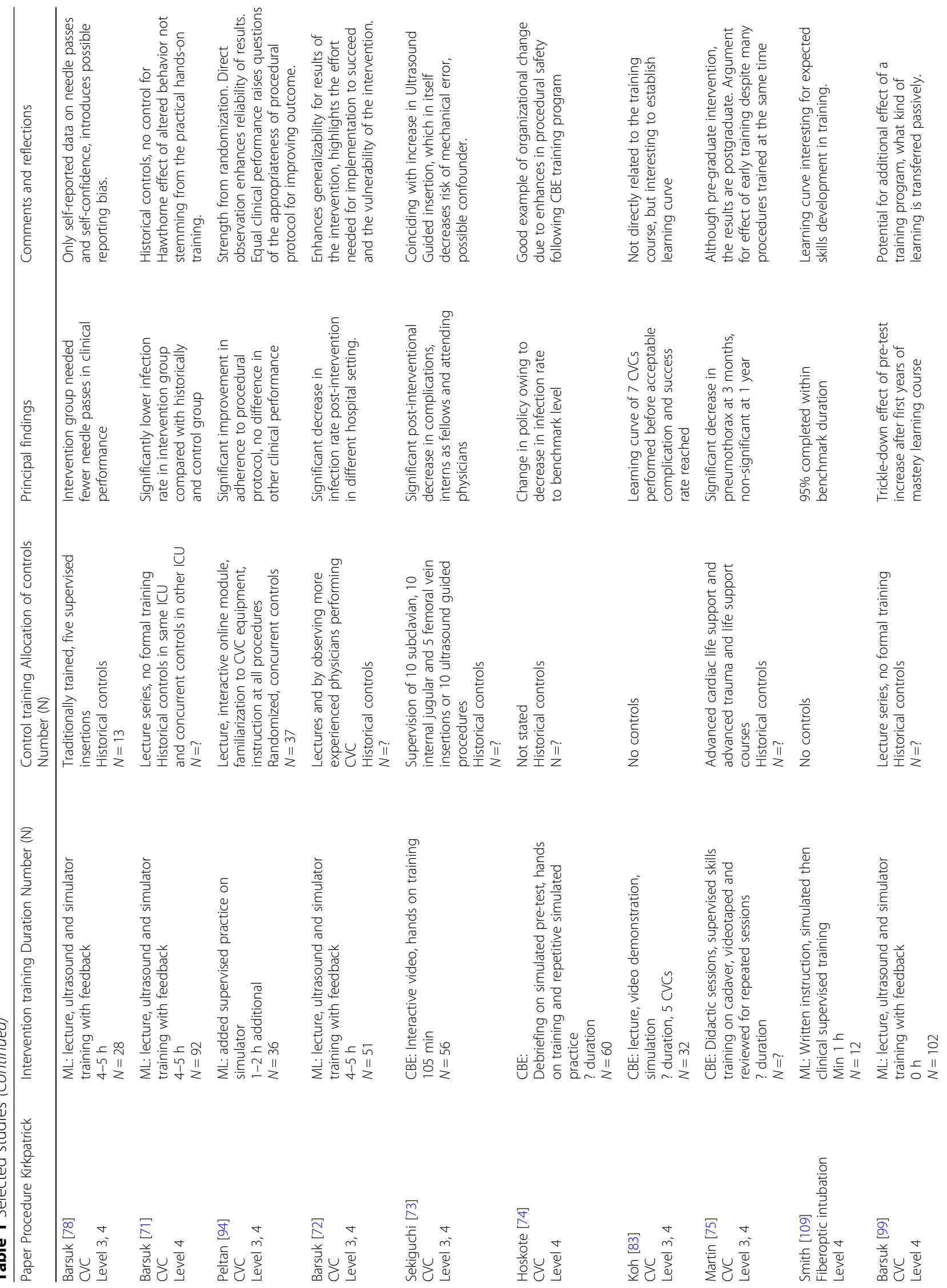




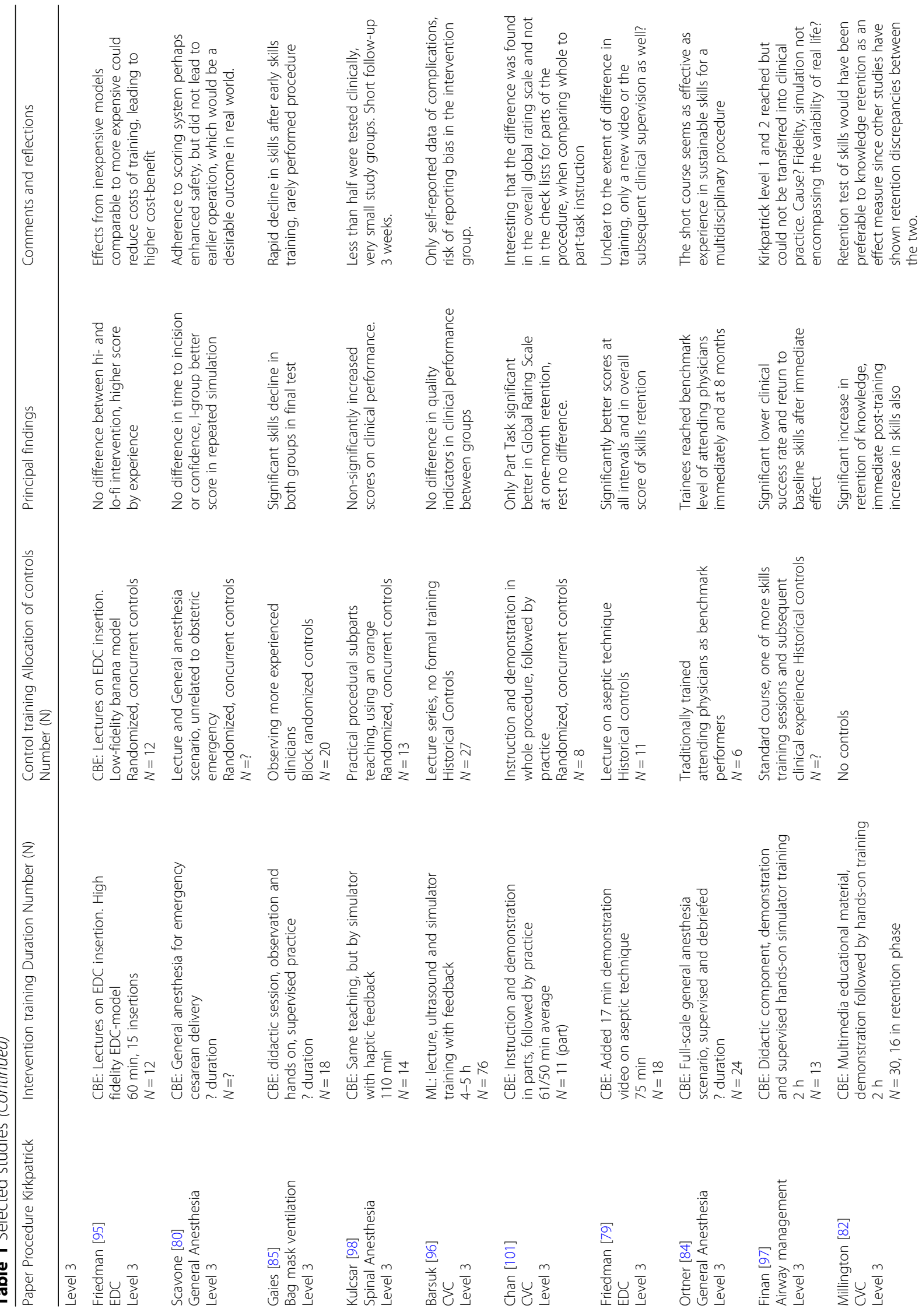




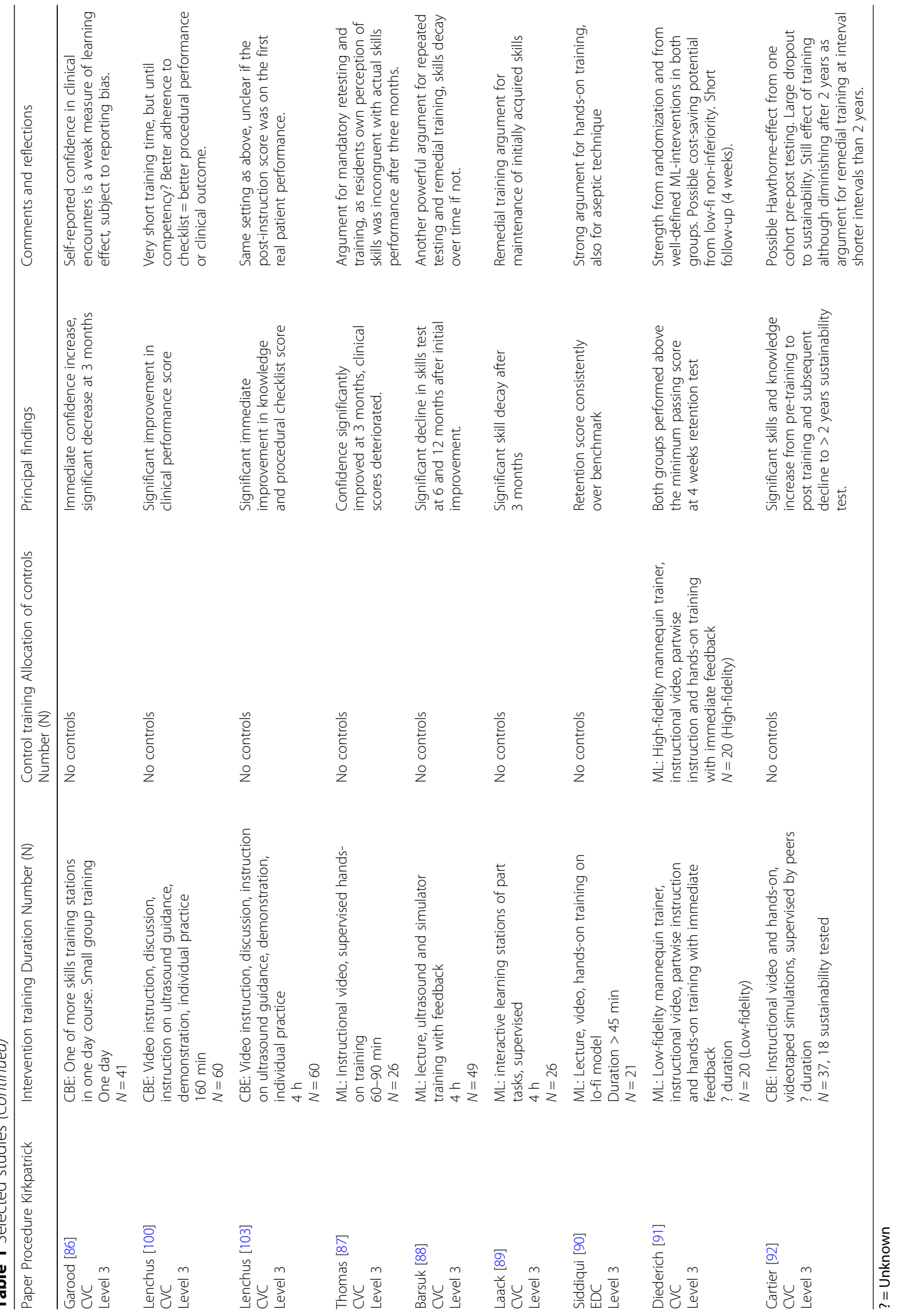


of complications and improved patient outcomes. The studies report return on investment in the range of a minimum of $\$ 63,000$ over 18 months up to $\$ 700,000$ per year [66-68], thus creating a strong argument for the investment in $\mathrm{CBE}$ for CVC-training.

In addition to the studies reporting return on investment, six studies show that CBE-training courses benefit patient care by significantly diminishing the complication rate in CVC placement [66-69, 71-75]. Furthermore, two studies demonstrate significantly fewer needle passes as a strong measure for decreased complications risk $[76,78]$. Although four studies show no difference $[70,81,93,94]$ and one a negative effect on success rate [77], these results indicate a positive effect on patient care from CBE-trained CVC insertion.

Twelve of the reviewed studies for level 3 fail to find lasting effects [81, 82, 85-89, 92, 95-97], and six struggle to find an initial effect for the immediate skill transfer to patient care [70, 80, 93, 95, 96, 98]. This contrast to the predominantly positive results from levels 5 and, in part, 4 is interesting. The reason for this contrast to higher-level studies could be that non-effective lower-level studies would not lead to the research of higher-level effects, due to the sequential nature of Kirkpatrick's model [53].

\section{Detailed findings \\ Kirkpatrick levels}

The causality of Kirkpatrick higher-level learning outcomes warrants precaution if learning outcomes at lower levels have not been evaluated sufficiently [57]. It is thus preferable to demonstrate effects from training at the lower levels before attempting to prove higher-level gains $[53,55]$.

Of the three studies reporting level 5 results, the studies by Cohen and Sherertz satisfies this requirement of sequential training evaluation. Sherertz in the same study evaluates trainees' satisfaction, change in clinical behavior, and the ensuing decrease in complication rate, which leads to the economic return on investment [68]. Cohen [67] inherits the sequential effects of the lower-level effects from investigating the same intervention in previous studies.

The studies from Cohen, Barsuk and coworkers are textbook examples of the stepwise evaluation of an educational intervention accommodating the Kirkpatrick principle $[67,71,78,88,96]$. The studies of the same intervention have established results from clinical performance and retention of skills by score cards, a decrease in the number of complications, and ultimately the positive return on investment in the Cohen paper [67]. The likelihood of the educational intervention being the cause of the higher-level effects therefore increases.

The dissemination study from Barsuk [72] shows that the same educational intervention can be transferred to a different hospital setting and still leads to improved patient safety and outcome at Kirkpatrick/Phillips level 4. Coupled with the trickle-down effect of the Barsuk 2011 study [99], it adds to the impression of a generalizable positive effect from the studied intervention. In this study, trainees showed improved pretraining procedural scores by simply observing their more experienced colleagues, who had already completed the program. This effect infers the possibility of raising the expected mastery level without adding cost, thus adding to the already established return on investment of the study by Cohen et al. [67].

\section{Educational strategy}

The investigated training courses are predominantly lectures and hands-on training of $45 \mathrm{~min}$ [90] to five hours [88] before allowing for clinical procedural performance on patients, either supervised or unsupervised. As critics have noted, these relatively short courses carry the risk of training for minimum requirements [33, 35].

When continued supervision in the clinical setting occurs, the supervisor can assist with further procedural instruction, which might enhance the procedural proficiency before independent performance. In the trial setting, the added clinical training represents a potential bias if differences in supervision between subjects are present.

In the unsupervised clinical performance, further development of skills is left to the trainees' own practice. The expected competence of the training course should thus be well defined and ensure a safe performance of the procedure following the course in order to minimize patient risk of complications.

Unfortunately, the transparency of competency level in the included CBE studies is not always as clear as CBE originally states. The problem, as we see it, is a loose competency definition. Thus, the necessary competency level before the trainee is allowed to progress to independent procedural performance is often defined in terms of subjective ratings. One author defines the prerequisite competence level as "practice repetitively until they felt comfortable" [100], and another uses experts' procedural performances as benchmarks, creating a level that comes close to an actual ML [84].

In contrast, $\mathrm{ML}$ is defined by high-standard learning goals, reached by continuous formative feedback. In the studies by Barsuk [71, 72, 78, 88, 96, 99], Cohen [67] and colleagues, a four-hour course of dedicated simulation-based ML was used for practicing central venous catheterization. These studies adhere to the principles of ML as defined by Bloom in his original work by using pretesting and training with immediate feedback until a predefined mastery level is reached. The positive results in all Kirkpatrick/Phillips levels of these studies, as earlier discussed, indicates that a focus on high mastery standards and feedback even in short ML 
courses enables the transfer of skills training to clinical performance and patient care and is cost-efficient.

\section{Control groups}

The use of control groups adds credibility to the results of a study by controlling for external factors influencing the results. Only applying extra attention to an intervention group additionally introduces the risk of a Hawthorne effect [58]. This effect can be estimated by granting a control group attention by subjecting them to a different intervention within the same time period.

Although a randomized controlled design is not easily applicable to educational interventions due to difficulty in blinding and the risk of rub-off effects, 11 of the included studies have done so to some extent $[69,70,76,77,80,81$, $85,94,95,98,101]$. By random allocation to groups, the underlying characteristics of the groups are thought to be evenly distributed, thus diminishing the bias of inherent differences in trainees [102].

Instead of randomization, a historical group at the same institution is used for control $[66-69,71-75,78,79,96$, 97, 99], which is thought to imply that the physical settings were identical. However, the temporal separation of the two groups will likely introduce confounders, such as changes in procedural guidelines, new equipment or differences in patient characteristics. Attempting to bridge this difference, some papers report patient and trainee characteristics $[74,76]$ while also declaring differences in guidelines, practices or other confounders.

In addition to including a control group, the description of control group training is important for the evaluation of the effect of the study. Unfortunately, description detail of control group training varies widely in the studies. Exemplary control group descriptions are primarily from studies defining a control group receiving a different, but still novel, training regime $[70,73,77,94]$. At the other end of the detail spectrum, studies describe the training received by controls as observing more experienced physicians before their own independent performances [68, 69, 85, 93].

In the ML studies by Barsuk, Evans, Cohen et al., the traditional training was five CVC insertions performed under supervision before the resident obtained the right to practice the procedure independently $[67,76,78]$. The intervention of a 4- to 5 -h course with a high passing standard thus represents a significant shift in the assessment of competence before independent practice and could be a key reason for the positive results of these studies.

\section{Measuring methods}

The fact that only three studies investigate Kirkpatrick/ Phillips level 5, return on investment, may be due to the time-consuming measurement, relying on valid clinical and economical information. Further, in keeping with the principles of Kirkpatrick/Phillips, only the interventions showing positive results in the lower levels of evaluation are eligible for higher-level evaluations $[53,55]$. This hierarchy results in the selection of only positive results of lower level studies for further investigations of higher-level outcomes.

Level 4 effects are primarily reported as decreases in patient complications or surrogate measures of these, such as the number of needle passes. We would argue that the actual number of complications should be the gold standard, although the surrogate measures are strong predictors of risk of complications [78]. For both level 4 and 5 studies, several confounding factors such as guideline changes, introduction of novel equipment or a shift in patient categories could induce doubt of the causality of effect. That 11 studies report positive level 4 and 5 effects nevertheless provides an indication of CBE and ML-based CVC training as being beneficial to both patient outcome and creating a return on investment.

Studies describing Kirkpatrick level 3 use both checklists identical to the ones used in the preclinical simulation setting $[77,79,98,103]$ and specific checklists developed for the clinical setting $[70,76,95,98]$ to determine the transfer and retention of skills. The criticism of checklist usage for evaluation of competence has previously been mentioned [35].

Using the same checklists for the skills measurement of the inexperienced and the proficient competence level could fail to recognize the traits of the expert. Experts rely upon pattern recognition cultivated by years of experience rather than on rigid task flow charts of competency training and assessment [36, 103, 104]. Proficient performers may thus receive low scores or even fail an assessment made for basic competence assessment.

Dwyer et al. proposes a solution to this challenge by using a modified Angoff method [105] to determine passing scores for residents at different levels of expertise. The study demonstrates a high correlation between judges, suggesting uniformity in the expected level of competence [105]. The included studies by Barsuk, Cohen, Diederich et al. [67, 71, 72, 78, 88, 91, 96, 99] also used the Angoff method to determine the minimal passing score used to determine mastery, although only for one level.

Retention of skills over time plays an important part in training, benefitting the intended patients for a longer period. The interval for the evaluation of retention in the included studies is variable and ranges from 4 weeks to over 2 years after the completion of the educational intervention [91, 92]. Short retention intervals may be insufficient to capture competence decay over time, whereas long intervals increase the risk that confounding factors will influence the results. The results of the reviewed studies show a predominant decrease in skills over time. 


\section{Strengths and limitations of the study design}

This review suffers from four potential limitations.

First, it focuses solely on basic procedural anesthesia skills training for novice trainees. As such, the conclusion we draw is of the basic level of skills acquisition. This induces a risk of overlooking the higher-level learning in more advanced proficiency training. Widening the scope of this study to include the higher-level training of more senior doctors would most likely have introduced an even larger heterogeneity of the included studies, making conclusions even more difficult to assert.

Second, the limitation of using the Kirkpatrick/Phillips model is its risk of oversimplifying the causality of training effect. Even if establishing effects on all five levels, efforts should be made to declare all other factors to solidify the conclusions of causality. This declaration is rarely done in the reviewed studies and thus introduces a bias to our conclusions that cannot be estimated.

Third, this review could be criticized for the same infallibility discourse by not questioning the structural concepts of CBE, as stated by Boyd [32]. We used an outcomes-based evaluation method to evaluate a likewise outcomes-based training method, which could be seen as a non-critical appraisal of CBE. Although we agree with the necessity for a critical approach to the conceptual constructs of behavioristic learning theory, this more theoretical discourse would be better served in a separate review.

Fourth, the purpose of a narrative review is to review the literature for strengths and weaknesses, gaps and areas for consolidation but without calculating effect sizes. The limitation of such a review is inversely linked to the adequacy, breadth and depth of the literature search. In our search, we incorporated several relevant databases and searched the references of the selected literature for gray literature. We thus believe that we have made an adequate effort to include all available literature, thereby adding strength to our conclusions.

\section{Implications for clinical implementation}

ML-based studies create the most consistent positive results in all Kirkpatrick/Phillips levels and thus appeal as the preferable learning strategy. As so many studies are investigating the same learning strategy and from the same study group, this would be stretching the conclusion a bit. The large heterogeneity of other studies, intervention, and assessment design adds to this caveat, making it difficult to systematically assess or calculate an aggregate effect of the studies. The often more rigorously defined mastery level together with continuous feedback could nevertheless be a way to achieve higher competence and thus counter the criticism of mediocrity.

When constructing CBE curricula, the medical educator must pay attention to the assessment methods. The
Angoff method is a widely accepted method of standards setting $[105,106]$. Using it to describe several levels of proficiency for the same competence or skill would further enable the continuous learning process and document the progress of the trainees.

The original Angoff method uses expert judges to determine an expected passing score for a level of proficiency [107]. In the modified version, multiple rounds of iterations are used to enhance agreement between the experts. Data from the resulting tests can then be used to further enhance the credibility of the passing score [108]. The Angoff method is thus not limited to determining the passing score of expected minimal competence but could be used for calculating scores for all levels of expertise [108]. Creating and using assessment standards for all expected competence levels would counter the criticism of promoting mediocrity and minimum standards.

Implementing novel training programs also requires careful planning. The description of the necessary efforts for the dissemination of a successful training program to a different setting from Barsuk spotlights the importance of an implementation strategy [72]. Identifying and securing the support of key players is vital in this process. If successful implementation is achieved, the trickle-down effect also from the same intervention holds the promise of an additional trade-off effect from the intervention [99].

\section{Future research directions}

The evidence from the three included studies demonstrating return on investment seems to indicate a substantial economic gain from especially ML and to a lesser extent CBE. Future studies should aim to replicate these results as well as those in levels 1-5 in different settings and define control groups vigorously in order to establish generalizability. Furthermore, comparing different training interventions could generate additional knowledge of the most effective way of conducting CBE training.

Increasing residents' contribution to clinical service could further add to the return on investment evaluation. Training in a more systematic way could enable earlier independent procedural performance while at the same time enhancing the quality and safety of the procedural performance. Thus, the gain from the intervention may be even greater than by decreased complications alone, providing further argument to medical educators looking for change.

Retention studies should aid in establishing an optimal interval for remedial training in order to maintain the originally learned skills. This could be achieved by sequential testing of residents at intervals after their initial training, determining when the skills decay results in subpar performance of the procedure. This time point would be variable, influenced by the procedure's complexity, performance 
frequency and the severity of the consequences from subpar performance. Potentially lifesaving, complex and seldom-performed procedures would thus warrant shorter interval for remedial training to ensure the expected standard.

\section{Conclusion}

It is a continuous challenge for educators and administrators to accommodate economical demands to train the best possible doctors within an acceptable time frame and at an acceptable cost. ML seems to satisfy both factors at the basic graduate anesthesia education level. High mastery level increases the competence level expected of the competent junior doctor while keeping in line with the outcome-focused CBE.

In conclusion, medical researchers evaluating the effects of CBE and ML in basic anesthesiology training should focus on both return on investment and patient-related outcomes in order to justify the enhanced supervision involved and cost of training. The evidence gained from future rigorous, controlled, stepwise educational evaluation studies would be a pivotal argument in favor of CBE and $\mathrm{ML}$ in the ongoing economic prioritization debate.

\section{Abbreviations}

CBE: Competency-based education; CVC: Central venous catheterization; EDC: Epidural catheter; ML: Mastery learning

\section{Funding}

No external funding was obtained.

\section{Availability of data and materials}

The datasets used and/or analyzed during the current study are available from the corresponding author on request.

\section{Authors' contributions}

All authors, CB, PM, SLMR, JKP and SAR, contributed to the design and focus of the review. CB did the preliminary search and selection from abstracts and titles, aided by PM. CB, PM, SLMR, JKP and SAR all participated actively in the extraction of data and the writing process of the final article. All authors, $C B$, PM, SLMR, JKP and SAR read and approved the final manuscript.

Ethics approval and consent to participate

No ethics approval was sought for this review as it only reviews already published research.

\section{Consent for publication}

Not applicable.

\section{Competing interests}

The authors declare that they have no competing interests.

\section{Publisher's Note}

Springer Nature remains neutral with regard to jurisdictional claims in published maps and institutional affiliations.

\section{Author details}

${ }^{1}$ Centre for Health Sciences Education, Faculty of Health, Aarhus University, Palle Juul Jensens Boulevard 82, Building B, DK-8200 Aarhus N, Denmark. ${ }^{2}$ Department of Paediatrics and Adolescent Medicine, Aarhus University Hospital, Palle Juul Jensens Boulevard 99, DK-8200 Aarhus N, Denmark. ${ }^{3}$ Department of Anaesthesiology and Intensive Care, South Section, Aarhus University Hospital, Tage-Hansens Gade 2, 8000 Aarhus C, Denmark.
${ }^{4}$ Department of Anesthesiology and Intensive Care, North Section, Aarhus University Hospital, Nørrebrogade 44, 8000 Aarhus C, Denmark.

Received: 22 October 2017 Accepted: 19 June 2018

Published online: 28 June 2018

References

1. lobst WF, Sherbino J, Cate O, Ten RDL, Dath D, Swing SR, et al. Competency-based medical education in postgraduate medical education. Med Teach [Internet]. 2010;32:651-6.

2. Mcgaghie WC, Mastery Learning. It is time for medical education to join the 21st century. Acad Med. 2015;90:1438-41.

3. Morcke AM, Dornan T, Eika B. Outcome (competency) based education: an exploration of its origins, theoretical basis, and empirical evidence. Adv Heal Sci Educ. 2013;18:851-63.

4. Carroll JB. The Carroll model: a 25-year retrospective and prospective view. Educ Res [Internet]. 1989;18:26-31. Available from: http://edr.sagepub.com/ cgi/doi/10.3102/0013189X018001026.

5. Keller FS. Good-bye, teacher. J Appl Behav Anal. 1968:79-89.

6. Harden RM, AMEE Guide No. 14. Outcome-based education: Part 1-An introduction to outcome-based education. Med Teach. 1999;21:7-14. Available from: https://doi.org/10.1080/01421599979969.

7. Cohen ER, Barsuk JH, McGaghie WC, Wayne DB. Raising the bar: reassessing standards for procedural competence. Teach Learn Med. 2013;25:6-9. United States; Available from: https://www.tandfonline.com/doi/abs/10. 1080/10401334.2012.741540?journalCode=ht/m20.

8. Bloom BS. Learning for mastery. Instruction and curriculum. Regional education Laboratory for the Carolinas and Virginia, topical papers and reprints, number 1. Eval comment. 1968;1(2):n2.

9. Keller FS. Engineering personalized instruction in the classroom. Rev Interamer Piscol. 1967;1:189-97.

10. Block JH, Burns RB. 1: Mastery Learning $\backslash$ Rev Res Educ [Internet]. 1976;4:349. Available from: http://rre.sagepub.com/cgi/doi/10.3102/ $0091732 \times 004001003$.

11. McGaghie WC, Miller GE, Sajid AW, Telder T V. Competency-based curriculum development on Med Educ: an introduction. Public Health Pap [Internet]. 1978;11-91. Available from: https://eric.ed.gov/?id=ED168447.

12. Ten Cate O. Competency-Based Postgraduate Med Educ: Past, Present and Future. GMS J Med Educ [Internet]. 2017;34:Doc69. Available from: https:// www.ncbi.nlm.nih.gov/pmc/articles/PMC5704607/.

13. Swing SR. The ACGME outcome project: retrospective and prospective. Med Teach. 2007;29:648-54

14. Frank JR, Danoff D. The CanMEDS initiative: implementing an outcomesbased framework of physician competencies. Med. Teach. 2007;29:642-7.

15. Gruppen LD, Mangrulkar RS, Kolars JC, Frenk J, Chen L, Bhutta Z, et al. The promise of competency-based education in the health professions for improving global health. Hum Resour Health [Internet]. 2012;10:43. Available from: http://human-resources-health.biomedcentral.com/articles/10.1186/ 1478-4491-10-43.

16. Ross FJ, Metro DG, Beaman ST, Cain JG, Dowdy MM, Apfel A, et al. A first look at the accreditation Council for Graduate Medical Education anesthesiology milestones: implementation of self-evaluation in a large residency program. J Clin Anesth Elsevier Inc. 2016;32:17-24. Available from: http://linkinghub.elsevier.com/retrieve/pii/S0952818016000477.

17. THE CCT IN ANAESTHETICS II: Competency Based Basic Level (Specialty Training (ST) Years 1 and 2) Training and Assessment A manual for trainees and trainers. London R Coll Anaesth. 2007. 2009;

18. THE CCT IN ANAESTHESIA III: Competency Based Intermediate Level (ST Years 3 and 4) Training and Assessment A manual for trainees and trainers. London R Coll Anaesth. 2007. 2007;

19. Ringsted C, Ostergaard D, CPM VDV. Implementation of a formal in-training assessment programme in anaesthesiology and preliminary results of acceptability. Acta Anaesthesiol Scand [Internet]. 2003;47:1196-203. Available from: http://doi.wiley.com/10.1046/j.1399-6576.2003.00255.x

20. Ringsted C, Henriksen AH, Skaarup AM, Van Der Vleuten CPM. Educational impact of in-training assessment (ITA) in postgraduate medical education: a qualitative study of an ITA programme in actual practice. Med Educ. 2004; 38:767-77.

21. Ringsted C, Østergaard D, Scherpbier A. Embracing the new paradigm of assessment in residency training: an assessment programme for first-year residency training in anaesthesiology. Med Teach. [Internet]. 2003;25:54-62. 
Available from: https://www.tandfonline.com/doi/abs/10.1080/ 0142159021000061431.

22. Rose SH, Long TR. Accreditation council for graduate medical education (ACGME) annual anesthesiology residency and fellowship program review: a "report card" model for continuous improvement. BMC Med Educ [Internet]. 2010;10:13. Available from: http://bmcmededuc.biomedcentral.com/articles/ 10.1186/1472-6920-10-13

23. Ostergaard D. National Medical Simulation training program in Denmark. Crit Care Med [Internet]. 2004;32:S58-60

24. Østergaard D, Lippert A, Ringsted C. Specialty training courses in Anesthesiology. Danish Soc Anesthesiol Intensive Med [Internet]. 2008;170: 1014.

25. ACGME. Report of the ACGME Work Group on Resident Duty Hours. 2002; 2002;1-9. Available from: http://www.acgme.org.

26. Lurie SJ. History and practice of competency-based assessment. Med Educ. 2012;46:49-57.

27. Ludmerer KM, Johns MME, A F, K L, A F, LT C, et al. Reforming Graduate Med Educ Jama [Internet]. 2005;294:1083. Available from: http://jama. jamanetwork.com/article.aspx?doi=10.1001/jama.294.9.1083

28. Engel GL. Clinical Observation. The Neglected Basic Method of Medicine JAMA [Internet]. 1965;192:849. Available from: http://jama.jamanetwork.com/ article.aspx?doi=10.1001/jama.1965.03080230055014.

29. Ebert TJ, Fox CA. Competency-based Education in Anesthesiology. Anesthesiology [Internet]. 2014;120:24-31. Available from: http:// anesthesiology.pubs.asahq.org/Article.aspx?doi=10.1097/ALN. 0000000000000039

30. Long DM. Competency-based Residency Training: The Next Advance in Graduate Medical Education. Acad. Med. [Internet]. 2000;75. Available from: http://journals.Iww.com/academicmedicine/Fulltext/2000/12000/ Competency_based_Residency_Training_The_Next.9.aspx.

31. Albanese MA, Mejicano G, Mullan P, Kokotailo P, Gruppen L. Defining characteristics of educational competencies. Med Educ. 2008:42:248-55.

32. Boyd VA, Whitehead CR, Thille P, Ginsburg S, Brydges R, Kuper A. Competency-based medical education: the discourse of infallibility. Med Educ. United States: Elsevier. 2017;91:1-13. Available from: https://doi.org/10, 1111/medu.13467.

33. Tooke J. Aspiring to excellence: final report of the independent inquiry into Modernising Medical Careers. http://www.asit.org/assets/documents/MMC FINAL_REPORT_REVD_4jan.pdf.

34. Touchie $\mathrm{C}$, Ten Cate $\mathrm{O}$. The promise, perils, problems and progress of competency-based medical education. Med Educ. 2016;50:93-100

35. Brooks MA. Med Educ and the tyranny of competency. Perspect Biol Med. 2009;52:90-102. Available from: http://muse.jhu.edu/article/258047.

36. Talbot M. Monkey see, monkey do: a critique of the competency model in graduate medical education. Med Educ. 2004;38:587-92.

37. Talbot M. Good wine may need to mature: a critique of accelerated higher specialist training. Evidence from cognitive neuroscience. Med Educ. 2004; 38:399-408.

38. Franzini L, Chen SC, McGhie Al, Low MD. Assessing the cost of a cardiology residency program with a cost construction model. Am Heart J. 1999;138: 414-21.

39. Norman G. Editorial - outcomes, objectives, and the seductive appeal of simple solutions. Adv Heal Sci Educ. 2006;11:217-20.

40. Kheterpal S, Tremper KK, Shanks A, Morris M. Six-year follow-up on work force and finances of the United States anesthesiology training programs: 2000 to 2006. Anesth Analg. 2009;108:263-72.

41. Bridges $M$, Diamond DL. The financial impact of teaching surgical residents in the operating room. Am J Surg. 1999;177:28-32.

42. Zeidel ML, Kroboth F, McDermot S, Mehalic M, Clayton CP, Rich EC, et al. Estimating the cost to departments of medicine of training residents and fellows: a collaborative analysis. Am J Med. 2005;1 18:557-64.

43. Danzer E, Dumon K, Kolb G, Pray L, Selvan B, Resnick AS, et al. What is the cost associated with the implementation and maintenance of an ACS/ APDS-based surgical skills curriculum? J Surg Educ Elsevier Inc. 2011;68:51925. Available from: https://doi.org/10.1016/j.jsurg.2011.06.004.

44. Ben-Ari R, Robbins RJ, Pindiprolu S, Goldman A, Parsons PE. The costs of training internal medicine residents in the United States. Am. J Med. Elsevier Inc. 2014;127:1017-23. Available from: https://doi.org/10.1016/j.amjmed. 2014.06.040.

45. Cook DA, Hatala R, Brydges R, Zendejas B, Szostek JH, Wang AT, et al. Technology-enhanced simulation for health professions education: a systematic review and meta-analysis. JAMA. 2011, 306:978-88. Available from: http://jama.jamanetwork.com/article.aspx?doi=10.1001/jama.2011.1234.

46. Sturm LP, Windsor JA, Cosman PH, Cregan PC, Hewett PJ, Maddern GJA. Systematic review of surgical skills transfer after simulation-based training. Ann Surg. 2008;248:166-79.

47. Threats to Graduate Medical Education Funding and the Need for a Rational Approach: A Statement From the Alliance for Academic Interna Medicine Ann Intern Med. 2011;155:461. Available from: http://annals.org/ article.aspx?doi=10.7326/0003-4819-155-7-201110040-00008.

48. Weinstein DF. The elusive goal of accountability in graduate medical education. Acad Med Int. 2015:90:1188-90.

49. McGaghie WC, Issenberg SB, Barsuk JH, Wayne DB. A critical review of simulation-based mastery learning with translational outcomes. Med Educ England. 2014:48:375-85.

50. Cox T, Seymour N, Stefanidis D. Moving the needle: Simulation's Impact on Patient Outcomes. Surg Clin North Am. 2015;95:827-38.

51. Zendejas B, Brydges R, Wang AT, Cook DA. Patient outcomes in simulation-based medical education: a systematic review. J Gen Intern Med. 2013;28:1078-89. Available from: http://link.springer.com/10.1007/ s1 1606-012-2264-5.

52. Lowry EA, Porco TC, Naseri A. Cost analysis of virtual-reality phacoemulsification simulation in ophthalmology training programs. J. Cataract refract. Surg. ASCRS and ESCRS. 2013;39:1616-7. Available from: https://doi.org/10.1016/j.jcrs.2013.08.015.

53. Kirkpatrick DL. Evaluating training programs. Tata McGraw-hill. Education. 1975.

54. Bates R. A critical analysis of evaluation practice: the Kirkpatrick model and the principle of beneficence. Eval Program Plann. 2004;27:341-7.

55. Phillips J, Phillips P. Using Roi to demonstrate performance value in the public sector. Perform Improv. 2009;48:22-8.

56. Bewley WL, O'Neil HF. Evaluation of medical simulations. Mil Med [Internet]. 2013:178:64-75. Available from: https://doi.org/10.7205/MILMED-D-13-00255

57. Arthur $\mathrm{W} \mathrm{Jr}$, Bennett $\mathrm{W} \mathrm{Jr}$, Edens PS, Bell ST. Effectiveness of training in organizations: a meta-analysis of design and evaluation features. J Appl Psychol. 2003;88:234-45.

58. McCambridge J, Witton J, Elbourne DR. Systematic review of the Hawthorne effect: new concepts are needed to study research participation effects. J. Clin. Epidemiol. [internet]. Elsevier Inc. 2014;67:267-77. Available from: https://doi.org/10.1016/j.jclinepi.2013.08.015

59. Frank JR, Mungroo R, Ahmad Y, Wang M, De Rossi S, Horsley T. Toward a definition of competency-based education in medicine: a systematic review of published definitions. Med Teach. 2010;32:631-7.

60. Colliver JA, Kucera K, Verhulst SJ. Meta-analysis of quasi-experimental research: are systematic narrative reviews indicated? Med Educ. 2008;42:858-65.

61. Lorello GR, D a C, Johnson RL, Brydges R. Simulation-based training in anaesthesiology: a systematic review and meta-analysis. Br J Anaesth. 2014; 112:231-45.

62. Ferrari R. Writing narrative style literature reviews. Eur Med Writ Assoc. 2015; 24:230-5.

63. Schardt C, Adams MB, Owens T, Keitz S, Fontelo P. Utilization of the PICO framework to improve searching PubMed for clinical questions. BMC Med Inform Decis Mak. 2007;7:16. Available from: http://www.biomedcentral. com/1472-6947/7/16.

64. Davies KS. Evidence Based Library and Information Practice 2011;75-80.

65. Haddaway NR, Collins AM, Coughlin D, Kirk S. The role of google scholar in evidence reviews and its applicability to grey literature searching. PLoS One. 2015;10:1-17.

66. Burden AR, Torjman MC, Dy GE, Jaffe JD, Littman JJ, Nawar F, et al. Prevention of central venous catheter-related bloodstream infections: is it time to add simulation training to the prevention bundle? I Clin Anesth United States. 2012;24:555-60.

67. Cohen ER, Feinglass J, Barsuk JH, Barnard C, O'Donnell A, McGaghie WC, et al. Cost savings from reduced catheter-related bloodstream infection after simulation-based education for residents in a medical intensive care unit. Simul. Healthc. United States; 2010 [cited 2014 Mar 27];5:98-102. Available from: https://insights.ovid.com/pubmed?pmid=20389233.

68. Sherertz RJ, Ely EW, Westbrook DM, Gledhill KS, Streed SA, Kiger B, et al. Education of physicians-in-training can decrease the risk for vascular catheter infection. Ann. Intern. Med. UNITED STATES. 2000;132:641-8.

69. Khouli H, Jahnes K, Shapiro J, Rose K, Mathew J, Gohil A, et al. Performance of medical residents in sterile techniques during central vein catheterization: 
randomized trial of efficacy of simulation-based training. Chest. United States. 2011;139:80-7.

70. Britt RC, Novosel TJ, Britt LD, Sullivan M. The impact of central line simulation before the ICU experience. Am. J. Surg. United States: Elsevier Inc; 2009;197: 533-6. Available from: https://doi.org/10.1016/j.amjsurg.2008.11.016

71. Barsuk JH, Cohen ER, Feinglass J, McGaghie WC, Wayne DB. Use of simulation-based education to reduce catheter-related bloodstream infections. Arch Intern Med. 2009;169:1420-3.

72. Barsuk JH, Cohen ER, Potts S, Demo H, Gupta S, Feinglass J, et al. Dissemination of a simulation-based mastery learning intervention reduces central line-associated bloodstream infections. BMJ Qual. Saf. England. 2014; 23:749-56.

73. Sekiguchi H, Tokita JE, Minami T, Eisen LA, Mayo PH, Narasimhan M. A prerotational, simulation-based workshop improves the safety of central venous catheter insertion: results of a successful internal medicine house staff training program. Chest 2011 [cited 2014 Apr 9];140:652-8. Available from: https://journal.chestnet.org/article/S0012-3692(11)60470-4/fulltext.

74. Hoskote SS, Khouli H, Lanoix R, Rose K, Aqeel A, Clark M, et al. Simulationbased training for emergency medicine residents in sterile technique during central venous catheterization: impact on performance, policy, and outcomes. Acad Emerg Med United States. 2015;22:81-7.

75. Martin M, Scalabrini B, Rioux A, Xhignesse M-A. Training fourth-year medical students in critical invasive skills improves subsequent patient safety. Am Surg. United States. 2003;69:437-40. Available from: https://search.proquest. com/openview/2a4cd24b7e29266b42969c16ffd0c441/1?pq-origsite= gscholar\&cbl=49079

76. Evans L V, Dodge KL, Shah TD, Kaplan LJ, Siegel MD, Moore CL, et al. Simulation training in central venous catheter insertion: improved performance in clinical practice. Acad. Med. United States; 2010 [cited 2014 May 26];85:1462-1469. Available from: https://insights.ovid.com/ pubmed?pmid=20736674.

77. Udani AD, Macario A, Nandagopal K, Tanaka MA, Tanaka PP. Simulationbased mastery learning with deliberate practice improves clinical performance in spinal anesthesia. Anesthesiol. Res. Pract. A.D. Udani, Department of Anesthesiology, Perioperative and Pain Medicine, Stanford University, Stanford, United States. 2014;2014:659160. Available from: https:// www.ncbi.n/m.nih.gov/pmc/articles/PMC4124787/.

78. Barsuk JH, McGaghie WC, Cohen ER, Balachandran JS, Wayne DB. Use of simulation-based mastery learning to improve the quality of central venous catheter placement in a medical intensive care unit. J Hosp Med United States. 2009:4:397-403.

79. Friedman Z, Siddiqui N, Mahmoud S, Davies S. Video-assisted structured teaching to improve aseptic technique during neuraxial block. $\mathrm{Br} J$ Anaesth England. 2013;111:483-7.

80. Scavone BM, Toledo P, Higgins N, Wojciechowski K, McCarthy RJ. A randomized controlled trial of the impact of simulation-based training on resident performance during a simulated obstetric anesthesia emergency. Simul. Healthc. United States. 2010;5:320-4.

81. Smith CC, Huang GC, Newman LR, Clardy PF, Feller-Kopman D, Cho M, et al. Simulation training and its effect on long-term resident performance in central venous catheterization. Simul. Healthc. United States. 2010:5:146-51.

82. Millington SJ, Wong RY, Kassen BO, Roberts JM, Ma IWY. Improving internal medicine residents' performance, knowledge, and confidence in central venous catheterization using simulators. J. Hosp. Med. United States. 2009;4: $410-6$.

83. Koh J, Xu Y, Yeo L, Tee A, Chuin S, Law J, et al. Achieving optimal clinical outcomes in ultrasound-guided central venous catheterizations of the internal jugular vein after a simulation-based training program for novice learners. Simul. Healthc. United States. 2014;9:161-6.

84. Ortner CM, Richebe P, Bollag LA, Ross BK, Landau R. Repeated simulationbased training for performing general anesthesia for emergency cesarean delivery: long-term retention and recurring mistakes. Int J Obstet Anesth Netherlands. 2014;23:341-7.

85. Gaies MG, Morris SA, Hafler JP, Graham DA, Capraro AJ, Zhou J, et al. Reforming procedural skills training for pediatric residents: a randomized, interventional trial. Pediatrics [Internet]. United States; 2009;124:610-9. Available from: http://www.ncbi.nlm.nih.gov/pubmed/19651582.

86. Garrood T, lyer A, Gray K, Prentice H, Bamford R, Jenkin R, et al. A structured course teaching junior doctors invasive medical procedures results in sustained improvements in self-reported confidence. Clin Med England. 2010;10:464-7.
87. Thomas SM, Burch W, Kuehnle SE, Flood RG, Scalzo AJ, Gerard JM. Simulation training for pediatric residents on central venous catheter placement: a pilot study. Pediatr Crit Care Med United States. 2013;14:e416-23.

88. Barsuk JH, Cohen ER, McGaghie WC, Wayne DB. Long-term retention of central venous catheter insertion skills after simulation-based mastery learning. Acad. Med. United States. 2010;85:S9-12. Available from: https:// insights.ovid.com/pubmed?pmid=20881713.

89. Laack TA, Dong Y, Goyal DG, Sadosty AT, Suri HS, Dunn WF. Short-term and long-term impact of the central line workshop on resident clinical performance during simulated central line placement. Simul Healthc United States. 2014;9:228-33.

90. Siddiqui NT, Arzola C, Ahmed I, Davies S, Carvalho JCA. Low-fidelity simulation improves mastery of the aseptic technique for labour epidurals: an observational study. Can J Anaesth United States. 2014;61:710-6.

91. Diederich E, Mahnken JD, Rigler SK, Williamson TL, Tarver S, Sharpe MR. The effect of model fidelity on learning outcomes of a simulation-based education program for central venous catheter insertion. Simul Healthc. 2015;10:360-7.

92. Cartier V, Inan C, Zingg W, Delhumeau C, Walder B, Savoldelli GL. Simulation-based medical education training improves short and longterm competency in, and knowledge of central venous catheter insertion: A before and after intervention study. Eur. J. Anaesthesiol. [Internet]. 2016;33:568-74. Available from: https://insights.ovid.com/ pubmed?pmid $=27367432$.

93. Miranda JA, Trick WE, Evans AT, Charles-Damte M, Reilly BM, Clarke P. Firmbased trial to improve central venous catheter insertion practices. J Hosp Med United States. 2007;2:135-42.

94. Peltan ID, Shiga T, Gordon JA, Currier PF. Simulation Improves Procedural Protocol Adherence During Central Venous Catheter Placement: A Randomized Controlled Trial. Simul Healthc. 2015;10:270-6. Available from: https://www.ncbi.nlm.nih.gov/pmc/articles/PMC4591105/.

95. Friedman Z, Siddiqui N, Katznelson R, Devito I, Bould MD, Naik V. Clinical impact of epidural anesthesia simulation on short- and long-term learning curve: High- versus low-fidelity model training. Reg Anesth Pain Med. United States; 2009;34:229-32. Available from: https://insights.ovid.com/ pubmed?pmid=19587620. [cited 2014 Mar 28].

96. Barsuk JH, McGaghie WC, Cohen ER, O'Leary KJ, Wayne DB. Simulationbased mastery learning reduces complications during central venous catheter insertion in a medical intensive care unit. Crit. Care Med. United States. 2009;37:2697-701. Available from: https://insights.ovid.com/ pubmed?pmid $=19885989$.

97. Finan E, Bismilla Z, Campbell C, Leblanc V, Jefferies A, Whyte HE. Improved procedural performance following a simulation training session may not be transferable to the clinical environment. J. Perinatol. Nat Publ Group. 2012; 32:539-44. Available from: https://doi.org/10.1038/jp.2011.141.

98. Kulcsar Z, O'Mahony E, Lovquist E, Aboulafia A, Sabova D, Ghori K, et al. Preliminary evaluation of a virtual reality-based simulator for learning spinal anesthesia. J Clin Anesth. 2013;25:98-105. Z. Kulcsár, Department of Anaesthesia and Intensive Care Medicine, Cork University Hospital, Cork, Ireland, United States. Available from: https://www.jcafulltextonline.com/ article/S0952-8180(12)00410-2/fulltext.

99. Barsuk JH, Cohen ER, Feinglass J, McGaghie WC, Wayne DB. Unexpected collateral effects of simulation-based medical education. Acad Med United States. 2011;86:1513-7. Available from: https://insights.ovid.com/ pubmed?pmid=22030762.

100. Lenchus J, Issenberg SB, Murphy D, Everett-Thomas R, Erben L, Arheart K, et al. A blended approach to invasive bedside procedural instruction. Med Teach England. 2011;33:116-23.

101. Chan A, Singh S, Dubrowski A, Pratt DD, Zalunardo N, Nair P, et al. Part versus whole: a randomized trial of central venous catheterization education. Adv Health Sci Educ Theory Pract. Springer Netherlands. 2015;20: 1061-71. Available from: https://doi.org/10.1007/s10459-015-9586-0.

102. Lachin JM, Matts JP, Wei LJ. Randomization in clinical trials: conclusions and recommendations. Control Clin Trials. 1988:9:365-74.

103. Smith AF, Greaves JD. Beyond competence: defining and promoting excellence in anaesthesia. Anaesthesia. 2010;65:184-91.

104. Patel BS, Feerick A. Will competency assessment improve the training and skills of the trainee anaesthetist? Anaesthesia. 2002;57:711-2. Available from: http://doi.wiley.com/10.1046/j.1365-2044.2002.27092.x.

105. Dwyer T, Wright S, Kulasegaram KM, Theodoropoulos J, Chahal J, Wasserstein $\mathrm{D}$, et al. How to set the bar in competency-based medical 
education: standard setting after an objective structured clinical examination (OSCE). BMC Med Educ. 2016;16(1) Available from: http://www. biomedcentral.com/1472-6920/16/1.

106. Barsuk JH, Cohen ER, Wayne DB, McGaghie WC, Yudkowsky R. A

Comparison of Approaches for Mastery Learning Standard Setting. Acad. Med. 2018:1. Available from: https://insights.ovid.com/pubmed?pmid= 29465449.

107. Norcini JJ. Standard setting on educational tests. Med Educ. 2003;37:464-9.

108. Ricker KL. Setting cut-scores: a critical review of the Angoff and modified Angoff methods. Alberta. J Educ Res. 2006;52:53-64.

109. Smith JE, Jackson AP, Hurdley J, Clifton PJ. Learning curves for fibreoptic nasotracheal intubation when using the endoscopic video camera. Anaesthesia. ENGLAND. 1997;52:101-6. Available from: https:/onlinelibrary. wiley.com/doi/abs/10.1111/j.1365-2044.1997.23-az023.x.

Ready to submit your research? Choose BMC and benefit from:

- fast, convenient online submission

- thorough peer review by experienced researchers in your field

- rapid publication on acceptance

- support for research data, including large and complex data types

- gold Open Access which fosters wider collaboration and increased citations

- maximum visibility for your research: over $100 \mathrm{M}$ website views per year

At BMC, research is always in progress.

Learn more biomedcentral.com/submissions 